\title{
Early exposure of the rat mammary gland to estrogen and progesterone blocks co-localization of estrogen receptor expression and proliferation
}

\author{
L Sivaraman, S G Hilsenbeck ${ }^{1}$, L Zhong, J Gay, O M Conneely, \\ D Medina and B W O'Malley
}

Department of Molecular and Cellular Biology, Baylor College of Medicine, Houston, Texas 77030, USA

${ }^{1}$ Breast Center, Baylor College of Medicine, Houston, Texas 77030, USA

(Requests for offprints should be addressed to B W O'Malley, Department of Molecular and Cellular Biology, Baylor College of Medicine, 1 Baylor Plaza, Houston, Texas 77030, USA; Email: berto@bcm.tmc.edu)

\begin{abstract}
An early single full-term pregnancy induces a long-lasting protective effect against mammary tumor development in humans and rodents. This protective effect can be mimicked in rats by short-term administration of estrogen and progesterone hormones prior to carcinogen administration. The hormones of pregnancy are able to induce a proliferative block upon carcinogen challenge that is not observed in the age-matched virgin. We wished to determine whether carcinogen is needed to induce a paracrine-to-autocrine shift of proliferation in steroid receptor positive cells or if such a cell population already exists in the age-matched virgin mammary gland. Here we show that estrogen receptor positive $(\mathrm{ER}+)$ proliferating
\end{abstract}

cells are rare in the developing mammary gland of the virgin rat but represent the majority of the proliferating cells in the mature (96-day-old) mammary gland of the virgin rat. As the majority of the proliferating cells before carcinogen challenge were ER positive, the ER+ proliferating cells in the mature mammary gland may represent the target cells for carcinogen-induced transformation. Importantly, prior exposure of the mammary gland to pregnancy levels of estrogen/progesterone blocked this positive association. This ability to block the proliferation of the ER + cells may be one factor by which pregnancy induces protection against breast cancer.

Journal of Endocrinology (2001) 171, 75-83

\section{Introduction}

An early full-term pregnancy inhibits human breast tumorigenesis (MacMahon et al. 1970, 1973, De Waard \& Trichopoulos 1988, De Waard 1992, Russo et al. 1992, Kelsey et al. 1993, Rosner et al. 1994). This result is mimicked in rodents by a full-term pregnancy (Gullino et al. 1975, Haslam 1979, Russo \& Russo 1980, Russo et al. 1982) or by exposure to estrogen and progesterone for 21 days (Grubbs et al. 1985, 1988, Sinha et al. 1988, Sivaraman et al. 1998, Guzman et al. 1999, Yang et al. 1999). One of the earliest consequences of the specific effect of estrogen/progesterone (E/P) is a block to methylnitrosourea (MNU)-induced proliferation at 6-8 days post-carcinogen treatment (Sivaraman et al. 1998). The molecular mechanism of this block is not understood.

Cell proliferation is indispensable for normal growth and development of the mammary gland. It has been shown in rats (Russo et al. 1999), mice (Brisken et al. 1998, 2000, Seagroves et al. 2000) and humans (Clarke et al. 1997, Shoker et al. 1999) that epithelial cell expression of estrogen receptor (ER) (and progesterone receptor (PR)) and that of proliferation-associated markers are almost mutually exclusive in the normal developing gland. This has been interpreted to mean that steroid receptors regulate proliferation in a paracrine fashion in the normal gland. It has been hypothesized that this organization is altered in the neoplastic state such that steroid receptors regulate proliferation in an autocrine fashion, representing an important pathogenetic step in the development of breast cancer.

In the current study, we have addressed the paracrineto-autocrine shift hypothesis in our rodent experimental model of mammary tumorigenesis. We wished to determine whether there are increased ER positive $(E R+)$ proliferating cells in animals that have not gone through pregnancy at or after carcinogen challenge and whether pregnancy is able to block this paracrine-to-autocrine shift of steroid receptor-regulated proliferation. We have shown here that a putative population of susceptible ER+ proliferating cells already exists in the mature rat mammary gland, which would likely give rise to tumors upon carcinogen challenge. Most importantly, our results 
Table $1 \mathrm{ER} / \mathrm{BrdU}$ analysis of young, adult, carcinogen-treated AMV and E/P-treated involuted rat mammary glands

\begin{tabular}{|c|c|c|c|c|c|c|c|c|}
\hline & $\begin{array}{l}\text { No. of } \\
\text { BrdU (\%) }\end{array}$ & $\begin{array}{l}\text { No. of } \\
\text { ER (\%) }\end{array}$ & $\begin{array}{l}\text { No. of } \\
\text { double (\%) }\end{array}$ & $\begin{array}{l}\text { No. of } \\
\text { DAPI }\end{array}$ & Expected (\%) & $\mathrm{O} / \mathrm{E}$ & Association & $P$ value \\
\hline \multicolumn{9}{|l|}{ Group } \\
\hline 45 day AMV ( - TEB) & $252(12 \cdot 4)$ & $842(41 \cdot 3)$ & $50(2 \cdot 5)$ & 2037 & $5 \cdot 12$ & $0 \cdot 49$ & Negative & $<0.001$ \\
\hline 96 day AMV & $69(4 \cdot 5)$ & $481(31 \cdot 6)$ & $38(2 \cdot 5)$ & 1523 & $1 \cdot 42$ & $1 \cdot 76$ & Positive & $<0.001$ \\
\hline 96 day $\mathrm{E} / \mathrm{P}$ & $15(1 \cdot 0)$ & $503(32 \cdot 9)$ & $4(0 \cdot 26)$ & 1529 & $0 \cdot 329$ & $0 \cdot 79$ & - & $0 \cdot 8$ \\
\hline 96 day $\mathrm{AMV}$ ( 7 day MNU) & $174 \quad(4 \cdot 3)$ & $1132(28 \cdot 2)$ & $60(1 \cdot 5)$ & 4013 & $1 \cdot 22$ & $1 \cdot 25$ & Positive & $0 \cdot 06$ \\
\hline 96 day E/P (7 day MNU) & $39(1 \cdot 7)$ & $685(29 \cdot 1)$ & $8(0 \cdot 34)$ & 2354 & $0 \cdot 48$ & $0 \cdot 71$ & - & $0 \cdot 29$ \\
\hline
\end{tabular}

At least five fields were captured per tissue section, at least one proliferating cell was included in each field of capture, and at least five animals were included in each group.

Expected $=$ the percentages of double-labeled cells that would be expected $(E)$ if the two variables were independent was calculated by multiplying the percentage of $\mathrm{ER}+$ and BrdU + cells and then dividing by 100 for each sample.

Observed/expected; $\mathrm{O} / \mathrm{E}=$ actual number of dual labeled cells counted/expected calculated as described above.

$\mathrm{O} / \mathrm{E}$ gives a ratio indication of whether receptor expression and proliferation are negatively or positively associated with each other and the strength of the association. In the former case, values less than 1 are expected and in the latter case, values greater than 1 are expected.

$P$ values for Fisher's exact test for independence.

have demonstrated the decreased frequency of this population of cells in E/P-treated mammary glands.

\section{Materials and Methods}

\section{Animals}

Female Wistar-Furth rats, 35 days old, were purchased from Harlen Sprague-Dawley, Indianapolis, IN, USA. The animals were acclimatized to our animal facility for 10 days prior to experimental manipulations. The animals were kept with unrestricted access to food and water, and housed under conditions of a $12 \mathrm{~h}$ light: $12 \mathrm{~h}$ darkness cycle.

\section{Experimental regime}

The experimental regimen to mimic pregnancy using E/P and preparation and administration of $\mathrm{MNU}$ to induce mammary tumors has been described before (Sivaraman et al. 1998). Briefly, 45-day-old Wistar-Furth rats were primed with $0.1 \mathrm{ml}$ solution of $2.5 \mu \mathrm{g}$ estradiol benzoate (E2B) s.c. Three days later the rats were treated with $20 \mu \mathrm{g}$ estrogen and $20 \mathrm{mg}$ progesterone, delivered in the form of beeswax pellets. After 21 days of hormone stimulation, the mammary glands were allowed to involute for 28 days. On day 96, the animals were administered $50 \mathrm{mg} / \mathrm{kg}$ body weight (BW) MNU, i.p. Mammary tissues were collected for experimentation at suitable time-points described below. Control animals received blank beeswax pellets. In the current studies there were five experimental animals in each group and at each time-point.

\section{Collection of tissues}

Mammary gland tissues were collected from untreated, E/P-treated and carcinogen-treated animals. The no. 4 abdominal glands were collected from 45- and 96-day-old virgin rat mammary glands, from 96-day-old E/P-treated/ involuted mammary glands and from age-matched virgin (AMV) and hormone treated/involuted mammary glands 3 days and 7 days post MNU administration. The tissues were processed as described below for dual immunofluorescent labeling.

\section{Double immunofluorescence labeling}

Animals were injected i.p. with bromodeoxyuridine (BrdU; $30 \mathrm{mg} / \mathrm{kg} \mathrm{BW}$; Sigma Chemical Co., St Louis, MO, USA) $2 \mathrm{~h}$ prior to their being killed. Tissues were fixed in chilled $4 \%$ paraformaldehyde in phosphatebuffered saline for $2 \mathrm{~h}$. Paraffin sections $(5-7 \mu \mathrm{m})$ were cut onto Probe-On Plus charged slides (Fisher Scientific, Pittsburgh, PA, USA). Sections were deparaffinized, hydrated through graded ethanols and subjected to microwave antigen retrieval in $10 \mathrm{mM}$ citrate buffer, pH 6.0 (Katoh et al. 1997). The tissues were blocked in 5\% normal goat serum. For ER/BrdU immunofluorescent labeling, sections were incubated sequentially with ER $\alpha$ antibody (1:300; MC-20, Santa Cruz, CA, USA), biotinylated goat anti-rabbit $\operatorname{IgG}(1: 500$; Vector laboratories, Inc., Burlingame, CA, USA), Texas Red (TR)conjugated streptavidin (1:250; Jackson ImmunoResearch Lab., West Grove, PA, USA), anti-BrdU antibody (1:50; Roche Diagnostic Corporation, Roche Biochemicals, Indianapolis, IN, USA) and fluorescein isothiocyanate (FITC)-conjugated goat anti-mouse $\operatorname{IgG}$ (1:20; Pierce, Rockford, IL, USA). For PR/BrdU dual immunofluorescence labeling the same protocol was used but a PR antibody (1:100; DAKO Corporation, Carpinteria, CA, USA) was used. All procedures were done at room temperature except the primary antibody incubations, which were carried out at $4{ }^{\circ} \mathrm{C}$, overnight. Slides were 


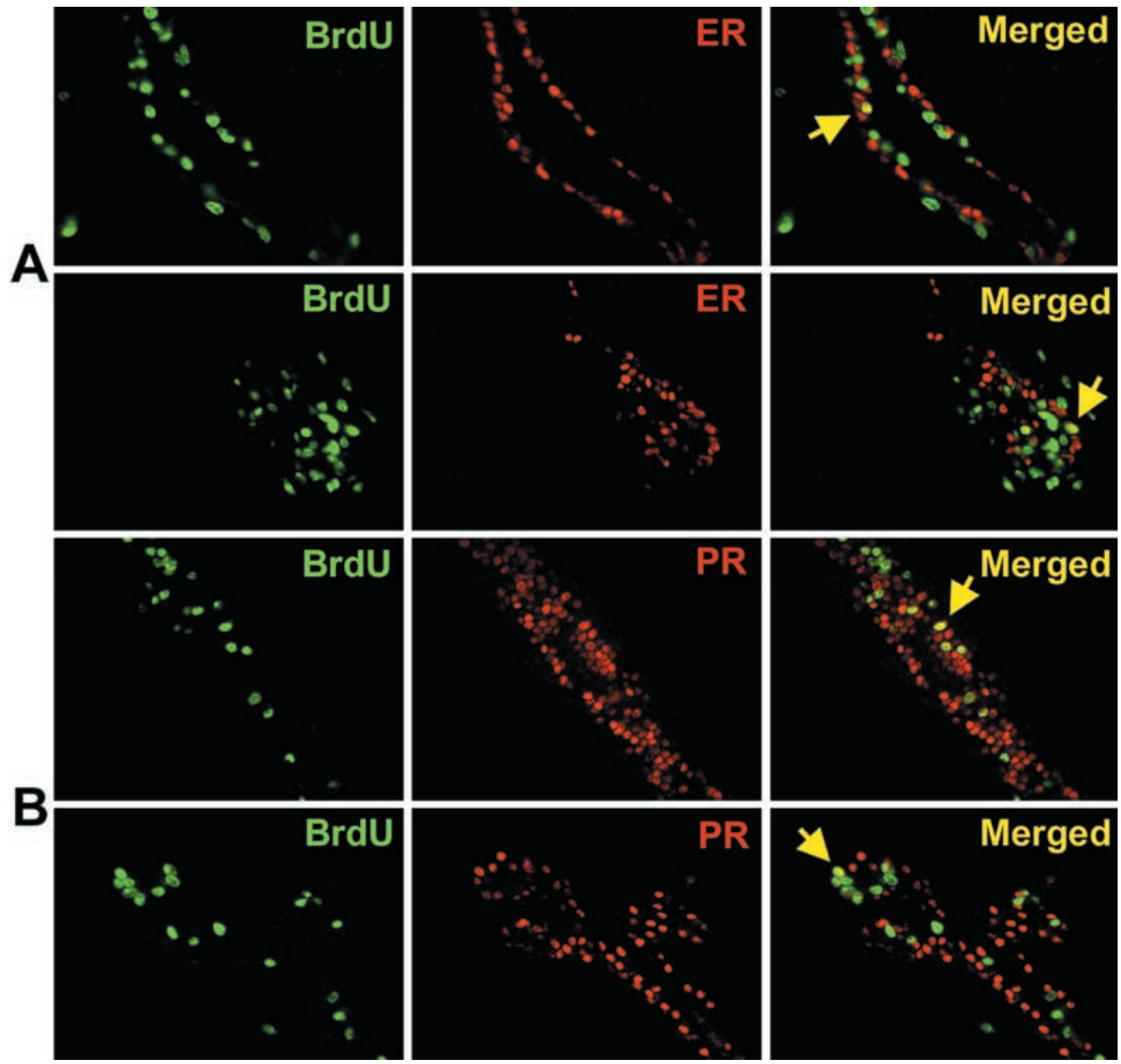

Figure 1 Pattern of distribution of ER+ and PR+ cells in relation to proliferating cells in the virgin rat mammary gland: 45-day-old female Wistar-Furth rats were injected with BrdU $2 \mathrm{~h}$ before they were killed. The no. 4 abdominal glands were excised and fixed in $4 \%$ paraformaldehyde. (A) Mammary glands stained simultaneously for ER (TR - red) using a rabbit polyclonal anti-ER antibody and for BrdU (FITC - green) using a mouse monoclonal anti-BrdU antibody. (B) Mammary glands were stained simultaneously for PR (TR - red) using a rabbit polyclonal anti-PR antibody and for BrdU (FITC - green) using a mouse monoclonal anti-BrdU antibody. Green and red images are superimposed in the panels indicated 'merged'. Arrows indicate cells in which ER/PR and BrdU are co-localized.

counterstained with 4',6-diamidino-2-phenylindole (DAPI) $(1: 1000$ of a $1 \mathrm{mg} / \mathrm{ml}$ solution; Sigma Chemical Co.) and mounted in Vectashield mounting medium (Vector laboratories, Inc.).

\section{Cell counting and analysis}

Images were captured using a Zeiss Axioskop microscope equipped with appropriate fluorescence filter sets coupled to a Hamamatsu C5810 CCD camera (Hamamatsu Corp., Bridgewater, NJ, USA) and processed using Adobe Photoshop 4.0 (Adobe Systems, Inc., San Jose, CA, USA). At least five individual fields were captured using a $\times 20$ lens and at least five animals were used in each experiment. Cells were counted using the Image Tool software (UTHSCSA, for Windows, version 2.0). 


\section{Statistical analysis}

Data obtained in the co-localization (ER vs BrdU) studies were analyzed using the Fisher's exact test for independence. Since separate analyses of animals of the same age and exposure history gave similar results, only the combined analyses are shown. The strength of the positive or negative association between ER positivity and proliferation (BrdU positive) was expressed as the ratio (observed/expected; O/E) of the observed proportion of cells staining for both ER and $\operatorname{BrdU}(\mathrm{O})$ to the proportion expected if the two characteristics were statistically independent $(\mathrm{E}=\%(\mathrm{ER}+) \times \%(\mathrm{BrdU}+) / 100)$. BrdU positivity and ER+ are treated as two separate assessments. Values greater than 1 indicate a positive association, values less than 1 indicate a negative association and values near 1 indicate no association (independence). Fisher's exact test was used to determine $P$ values.

\section{Results}

In the mammary gland, proliferation is regulated by the levels of estrogen and progesterone. Therefore, in this study we examined the relationship between steroid receptor expression and proliferation in the normal adult virgin rat mammary gland and the effect early exposure to $\mathrm{E} / \mathrm{P}$ had on this relationship. We have used a dual immunofluorescent labeling approach to detect steroid receptor and proliferation. The analysis was performed on paraffin-embedded tissue using an antigen-retrieval protocol in glands derived from 45-day-old virgin, $96 \mathrm{AMV}$, 96-day E/P-treated, 3-day and 7-day carcinogen-treated $\mathrm{AMV}$ and $\mathrm{E} / \mathrm{P}$ rats. Table 1 summarizes the data and all the statistical analysis. It is clear from Table 1 that proliferation in the AMV is higher than in the $\mathrm{E} / \mathrm{P}$-treated gland and all time-points examined, namely, 96 days, 3 days post-carcinogen and 7 days post-carcinogen. To our surprise the 96-day-old virgin rat mammary gland showed a significant number of $\mathrm{BrdU}$ positive cells (4.5\%). This is different from that which we reported earlier (Sivaraman et al. 1998) and we attribute this difference to the following reasons. (1) These experiments were designed specifically to find BrdU+ cells to examine for double labeling. Therefore our search was biased to include BrdU+ areas and was not a random analysis. (2) We examined both distal and proximal areas of the gland while the original study reported that the two portions of the gland are not equivalent with respect to the extent of proliferation. (3) Animals are likely to be in different estrous states but animals housed in the same cage are normally in the same estrous cycle. Therefore we cannot directly compare this study to our earlier study because the criteria/parameters were different. Importantly, however, the proliferation in the AMV group was significantly higher than in the E/P-treated group 7 days post MNU
$(P<0 \cdot 001)$ and corroborates our earlier finding (Sivaraman et al. 1998).

We next determined the correlation between the frequency of ER+ cells with the frequency and distribution of BrdU+ cells. $\mathrm{PR}+$ proliferating cells were also examined in a 45-day-old virgin and the 7-day carcinogen-treated mammary gland. The results are illustrated in Figs 1-3.

Figure $1 \mathrm{~A}$ and $\mathrm{B}$ depicts the dissociation of ER and PR expression with proliferation in a 45-day-old virgin mammary gland respectively. ER+ proliferating cells represent a numerically small population in a 45-day-old rat mammary gland and comprise $5.3 \%$ of the cells in the terminal end buds (TEB) and $2.5 \%$ of the cells in large ducts, small ducts and lobular structures of the mammary gland. Co-localized cells were predominantly found in small ducts and TEBs. The results support a negative association between proliferation and ER positivity. The percentage of co-localized cells was greater than that reported for 55-day-old rats by Russo et al. (1999) where the percentage of dual-labeled cells in TEBs was $1 \cdot 01 \%$ and that in alveolar buds and lobules $0.43 \%$. While both tritiated thymidine and BrdU are specific S-phase markers, the higher value might be attributed to the longer exposure time to the label $(2 \mathrm{~h}$ for $\operatorname{BrdU}$ vs $1 \mathrm{~h}$ for ${ }^{3} \mathrm{H}$-thymidine), a difference in rat strains used or just increased sensitivity of detecting incorporated BrdU compared with radiolabeled DNA. Figure 1B depicts the dissociation of $\mathrm{PR}$ expression and proliferation. In a 45 -day-old rat mammary gland, while approximately $47 \%$ of the luminal epithelial cells express PR, only $2 \cdot 6 \%$ of the $\mathrm{PR}+$ cells were proliferating. Thus $\mathrm{ER}+$ and $\mathrm{PR}+$ proliferating cells are a small population in the young virgin rat mammary gland.

We next examined proliferation in adult virgin and E/P-exposed rat mammary glands where TEBs are absent. The proliferation in the E/P-treated and AMV gland at 96 days was significantly different $(1 \%$ and $4.5 \%$ respectively, $P<0 \cdot 001)$; however, the percentages of ER + cells in the two groups were comparable $(32.9 \%$ and $31.6 \%$ respectively). More importantly, the frequency of duallabeled cells between the two groups was significantly different; $P \leq 0 \cdot 001$ (Table 1). The percentage of duallabeled cells in the 96-day-old AMV was $2 \cdot 5 \%$ and that in the E/P-treated 96-day-old animal $0 \cdot 26 \%$ (Table 1). Thus it appears that co-localization of ER and proliferation is abolished by hormone stimulation prior to carcinogen exposure.

Figure 2A clearly depicts the increased presence of ER+ proliferating cells in the AMV 3 days after carcinogen challenge $(1 \cdot 05 \%)$. The percentage of such dual-labeled cells in the glands that have been exposed to E/P remained low $(0 \cdot 06 \%$, Fig. 2B). Thus, prior exposure to hormones blocks the appearance of ER+ proliferating cells in the mammary gland while, in the adult gland, a significant portion of the proliferating cells are ER positive. 


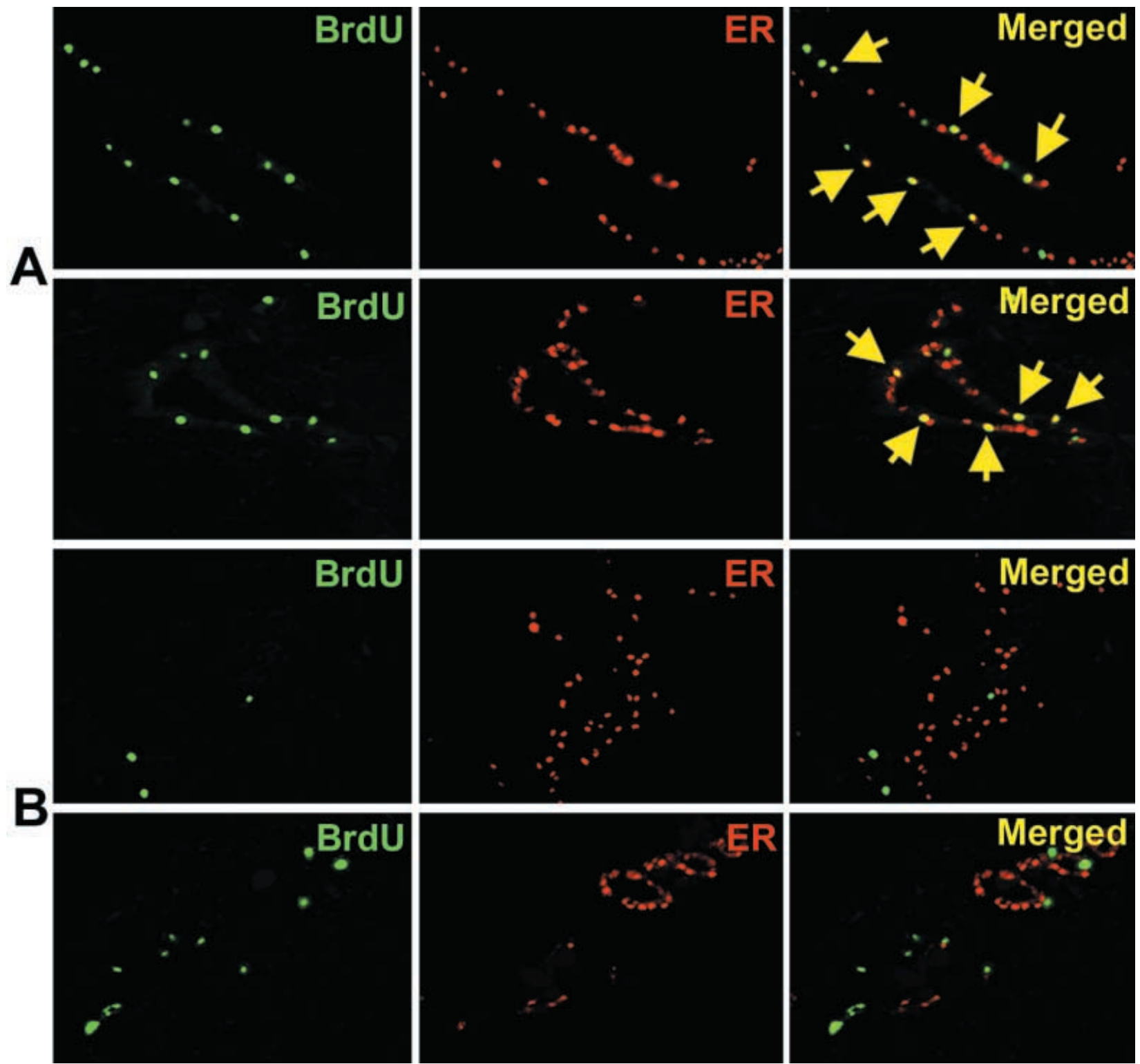

Figure 2 Absence of ER+ proliferating cells in E/P+ treated rat mammary glands 3 days after MNU administration: 45-day-old rats were primed with E2B for 3 days. They were then administered beeswax pellets containing $20 \mu \mathrm{g}$ estrogen and 20 mg progesterone for 21 days to mimic pregnancy. After 28 days of gland involution (96 days), the animals were administered $50 \mathrm{mg} / \mathrm{kg}$ BW MNU. Ninety-six-day-old AMV rats, treated with blank beeswax pellets were also administered $50 \mathrm{mg} / \mathrm{kg}$ BW MNU and served as control animals. Three days later the animals were injected with BrdU $2 \mathrm{~h}$ before being killed. The no. 4 abdominal glands were excised and fixed in $4 \%$ paraformaldehyde. Tissues were embedded in paraffin, sectioned and stained for ER and BrdU as detailed in Fig. 1. (A) AMV and (B) E/P-treated rats. Green and red images are superimposed in the panels indicated 'merged'. Arrows indicate cells in which ER and BrdU are co-localized.

Figure 3 confirms the presence of ER+ (Fig. 3A) and $\mathrm{PR}+$ (Fig. 3B) proliferating cells in the AMV 7 days after carcinogen exposure. Approximately $1.5 \%$ of the ER+ cells and $1.0 \%$ of the PR+ cells were proliferating in the AMV and only about $0.34 \%$ of the ER+ and $0.23 \%$ of the $\mathrm{PR}+$ cells were proliferating in the E/P-treated mammary glands.
In the present study, only the data for ER/BrdU were statistically analyzed since estrogen is the primary mitogenic hormone in the mammary gland. Table 1 summarizes in detail the percentage of cells staining for BrdU, ER, dual-labeled cells and the percentages of double-labeled cells that would be expected if the two variables were independent. We have used the $\mathrm{O} / \mathrm{E}$ 


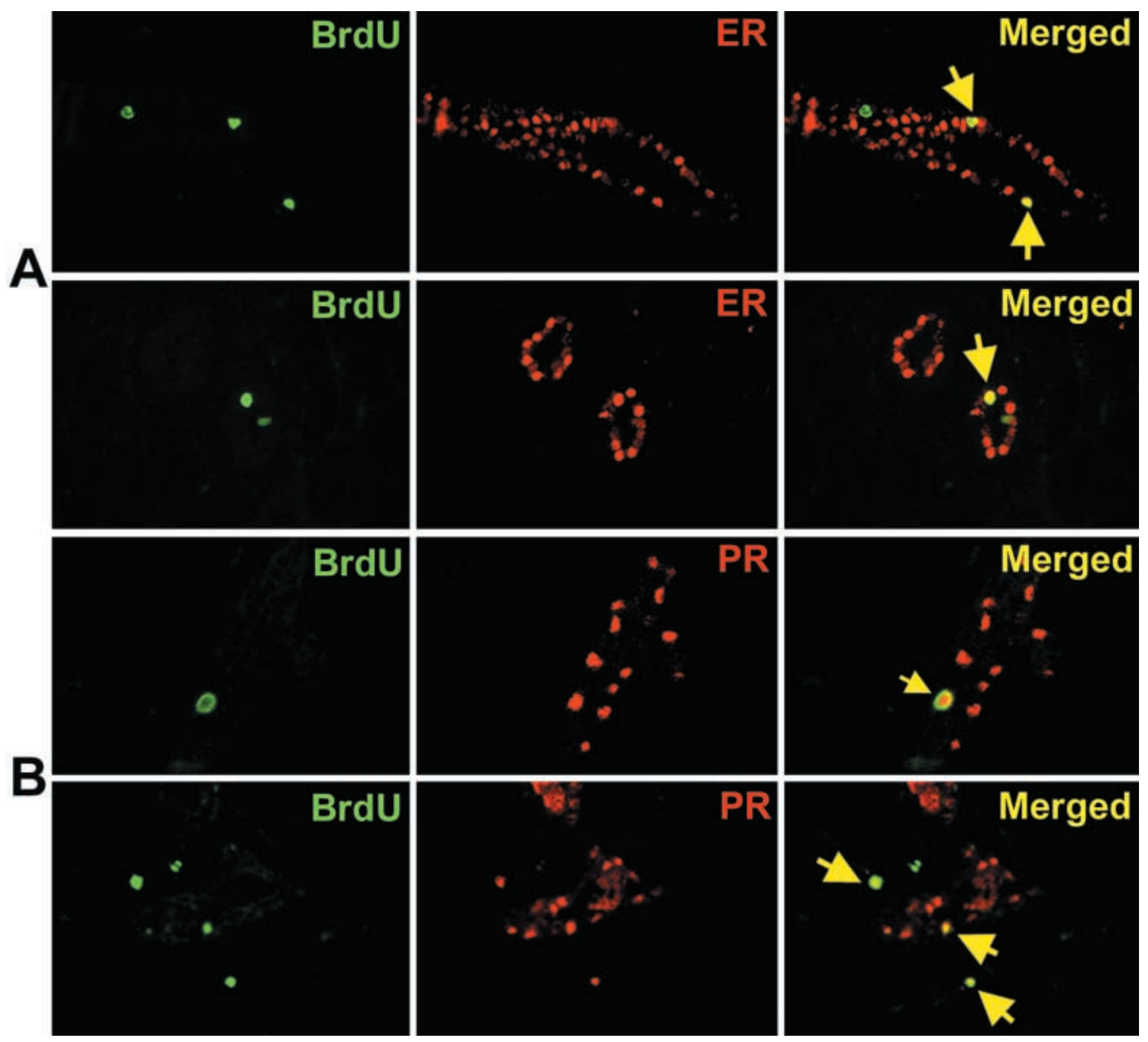

Figure 3 Co-localization of steroid receptors and proliferation upon carcinogen challenge: 96 -day-old rats were administered $50 \mathrm{mg} / \mathrm{kg}$ BW MNU. Seven days later, the animals were injected with $30 \mathrm{mg} / \mathrm{kg}$ BrdU $2 \mathrm{~h}$ before they were killed. The no. 4 abdominal glands were excised and fixed in $4 \%$ paraformaldehyde. Tissues were embedded in paraffin, sectioned and stained either for (A) ER and BrdU or (B) PR and BrdU by double immunofluorescent labeling (green - BrdU, red - PR/ER). Green and red images are superimposed in the panels indicated 'merged'. Arrows indicate cells in which ER/PR and BrdU are co-localized.

ratio to indicate whether the two markers are positively, negatively or not associated with each other (ratio of $>1,<1$ or $\approx 1$ respectively) and the strength of the association.

The O/E ratio for the mammary gland of a 45-day-old virgin was 0.48 for the TEBs and 0.49 for the remaining parts of the gland, revealing that receptor expression and proliferation are negatively associated. Thus, in the virgin rat mammary gland, receptor expression and proliferation are primarily mutually exclusive events.
Similar analysis was carried out in the AMV and E/P-treated glands at 96 days, and 3 and 7 days after MNU. On all of the 3 days the AMV always showed a positive association between receptor expression and proliferation (96 days $\mathrm{O} / \mathrm{E}=1 \cdot 76,3$ day $\mathrm{MNU} \mathrm{O} / \mathrm{E}=1 \cdot 98$, 7 day $\mathrm{MNU} \mathrm{O} / \mathrm{E}=1 \cdot 25)$. In sharp contrast, the $\mathrm{E} / \mathrm{P}$ treated gland always showed a numerically negative association between the two markers ( 96 days $\mathrm{O} / \mathrm{E}=0 \cdot 81,3$ day $\mathrm{MNU} \mathrm{O} / \mathrm{E}=0 \cdot 19,7$ day $\mathrm{MNU} \mathrm{O} / \mathrm{E}=0 \cdot 71)$, although only day 3 was statistically significant. 


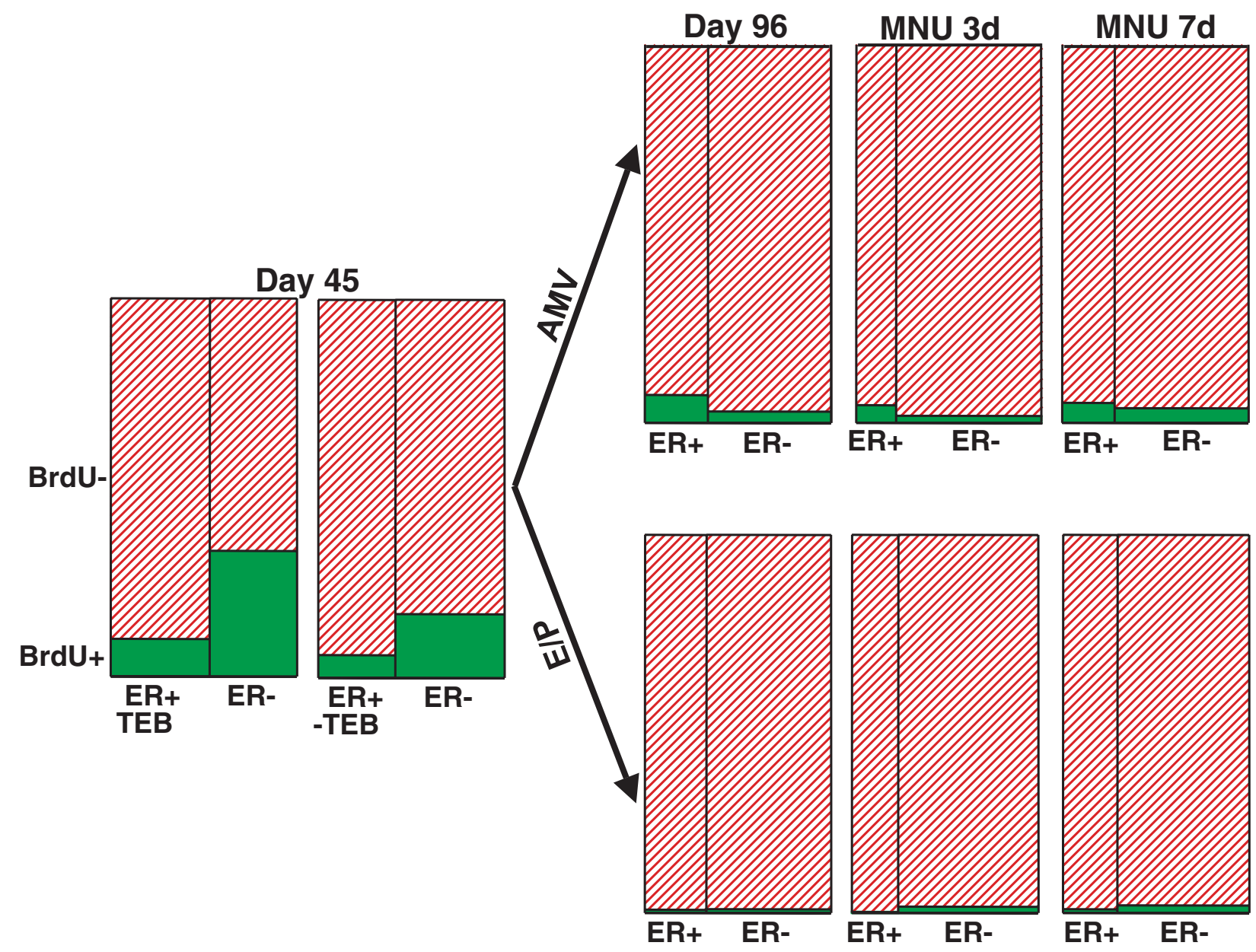

Figure 4 Graphical representation of ER BrdU labeling. The large boxes represent the total epithelial cells counted. The hatched red represents BrdU negative cells, the green represents BrdU + cells. The area included in a given color is directly proportional to the percent of cells for that character. Thus, the green area in the ER+ cells in the 45 -day-old rat represents $5 \cdot 3 \%$ in the TEBs and $2 \cdot 5 \%$ in the remaining parts of the gland of all cells counted in that group. The rat mammary gland has four populations of epithelial cells, namely, $\mathrm{ER}+$ proliferating and non-proliferating populations and ER negative proliferating and non-proliferating populations. A focus on the green boxes $(\mathrm{BrdU}+)$ shows the relative changes in $\mathrm{ER}+$ proliferating cells with gland development and with carcinogen treatment.

$\mathrm{E} / \mathrm{P}=$ estogen/progesterone; $\mathrm{d}=$ day.

\section{Discussion}

In the current study, we have shown that ER+ proliferating cells are rare in the developing mammary gland of a young virgin rat and the two markers, receptor expression and proliferation, are disjointed events. These results are consistent with the current hypothesis that ER-dependent regulation of proliferation is likely to be paracrine in the developing mammary gland of the young virgin rat. In contrast, in the mature gland of the virgin rat, although fewer cells are proliferating, the percentage of dual-labeled cells was significantly increased and the two markers were positively associated. In fact, over half of the proliferating cells are receptor positive in a 96-day-old virgin rat mammary gland. Positive association was observed before carcinogen challenge. Thus, contrary to common belief, mammary carcinogenesis does not necessarily involve a paracrine-to-autocrine switch in the regulation of proliferation by steroid receptors. Instead, the age-dependent proportionate increase in ER+ proliferating cells suggests that the autocrine pathway is already present in the mammary gland and the ER+ proliferating cells provide a likely target cell population for carcinogen-induced transformation. Finally, and most importantly, prior exposure of the mammary gland to pregnancy levels of estrogen and progesterone resulted in a failure of the mammary gland to attain a positive association between ER expression and proliferation. This might be one mechanism by which pregnancy induces protection against breast cancer, i.e. by blocking the ability 
of the ER+ cells to respond to an abnormal proliferative stimulus.

Our report is novel in that we have studied the responses of a mature mammary gland to carcinogenesis while earlier studies relating refractoriness induced by hormones have looked at young virgin mammary glands. The study of steroid receptors and their association with proliferation could clarify some features regarding the early phases of chemical carcinogenesis-induced neoplastic initiation and progression in the breast. Initiated breast cells could express a different regulation of proliferative activity and steroid receptor expression from the very beginning rather than as a result of a modulation during neoplastic progression. This relation may be different in an E/P-exposed mammary gland that is refractory to carcinogen-induced tumorigenesis. We have shown here that early exposure to $\mathrm{E} / \mathrm{P}$ in fact is able to block the autocrine regulation of proliferation by steroid receptors.

Figure 4 summarizes graphically the main results. In a 45-day-old virgin rat mammary gland there are two populations of epithelial cells, namely, an ER + population and an ER-amplifying population whose proliferation is regulated by the ER+ population in a paracrine fashion. With maturation of the gland and the attainment of a predominately quiescent proliferative state, ER + cells represent the major population of proliferating cells (Fig. 4, upper panel). Upon MNU exposure, the ER+ cells respond with a proliferative burst that is maintained for 7 days and also results in the recruitment of ER negative cells into the proliferating pool. Therefore, with maturation, proliferation is decreased in the transient amplifying population until the next need for rapid enlargement of the epithelial cell population, e.g. pregnancy.

The observation that hormones of pregnancy block the co-localization of ER expression and proliferation (shown in Fig. 4, lower panel) suggests that these hormones are able to alter the cell fate of mammary epithelial cells such that the putative susceptible population of mammary epithelial cells is abrogated by prior hormone exposure. We hypothesize that prior hormone stimulation results in a blocked proliferative response of $\mathrm{ER}+$ cell population to MNU. The susceptible ER+ population capable of proliferation continues to exist in the AMV and is the likely target of transformation upon carcinogen exposure. The molecular pathways that are responsible for the proliferation block and its regulation by $\mathrm{E} / \mathrm{P}$ are unknown at the present but represent a fertile area for investigation.

Co-expression of steroid receptor co-activators with steroid receptors and loss of the expression of tumor suppressor genes are likely mechanisms by which a disproportionate increase in the co-expression of steroid receptor and proliferation occurs with maturation of the mammary gland. Studies of the molecular pathways by which exposure to hormones result in maintaining the normal relationship between ER and cell proliferation could lead to the identification of molecules that mediate this process and alternative strategies in the prevention of breast cancer.

\section{Acknowledgement}

This work was supported by grant PO1CA64225.

\section{References}

Brisken C, Park S, Vass T, Lydon JP, O'Malley BW \& Weinberg RA 1998 A paracrine role for the epithelial progesterone receptor in mammary gland development. PNAS 95 5076-5081.

Brisken C, Heineman A, Chavarria T, Elenbaas B, Tan J, Dey SK, McMahon JA, McMahon AP \& Weinberg RA 2000 Essential function of Wnt-4 in mammary gland development downstream of progesterone signaling. Genes and Development 14 650-654.

Clarke RB, Howell A, Potten CS \& Anderson E 1997 Dissociation between steroid receptor expression and cell proliferation in the human breast. Cancer Research 7 4987-4991.

De Waard F 1992 Preventive intervention in breast cancer, but when? (see comments). European Journal of Cancer Prevention $\mathbf{1}$ 395-399.

De Waard F \& Trichopoulos D 1998 A unifying concept of the aetiology of breast cancer (see comments). International Journal of Cancer 41 666-669.

Grubbs CJ, Farnell DR, Hill DL \& McDonough KC 1985 Chemoprevention of N-nitroso-N-methylurea-induced mammary cancers by pretreatment with 17 beta-estradiol and progesterone. Journal of the National Cancer Institute 74 927-931.

Grubbs CJ, Juliana MM \& Whitaker LM 1988 Short-term hormone treatment as a chemopreventive method against mammary cancer initiation in rats. Anticancer Research 8 113-117.

Gullino PM, Pettigrew HM \& Grantham FH 1975 N-nitrosomethylurea as mammary gland carcinogen in rats. Journal of the National Cancer Institute 54 401-414.

Guzman RC, Yang J, Rajkumar L, Thordarson G, Chen X \& Nandi S 1999 Hormonal prevention of breast cancer: mimicking the protective effect of pregnancy. PNAS 96 2520-2525.

Haslam SZ 1979 Age as a modifying factor of 7,12-dimethylbenz(a)anthracene-induced mammary carcinogenesis in the Lewis rat. International Journal of Cancer 23 374-379.

Katoh AK, Stemmler N, Specht S \& D’Amico F 1997 Immunoperoxidase staining for estrogen and progesterone receptors in archival formalin fixed, paraffin embedded breast carcinomas after microwave antigen retrieval. Biotechnic and Histochemistry $\mathbf{7 2}$ 291-298.

Kelsey JL,Gammon MD \& John EM 1993 Reproductive factors and breast cancer. Epidemiological Reviews 15 36-47.

MacMahon B, Cole P, Lin TM, Lowe CR, Mirra AP, Ravnihar B, Salber EJ, Valaoras VG \& Yuasa S 1970 Age at first birth and breast cancer risk. Bulletin of the World Health Organization 43 209-221.

MacMahon B, Cole P \& Brown J 1973 Etiology of human breast cancer: a review. Journal of the National Cancer Institute $5021-42$.

Rosner B, Colditz GA \& Willett WC 1994 Reproductive risk factors in a prospective study of breast cancer: the Nurses' Health Study. American Journal of Epidemiology 139 819-835.

Russo J \& Russo H 1980 Susceptibility of the mammary gland to carcinogenesis. II. Pregnancy interruption as a risk factor in tumor incidence. American Journal of Pathology 100 497-512.

Russo J, Tay LK \& Russo IH 1982 Differentiation of the mammary gland and susceptibility to carcinogenesis. Breast Cancer Research and Treatment 2 5-73. 
Russo J, Rivera R \& Russo H 1992 Influence of age and parity on the development of the human breast. Breast Cancer Research and Treatment 23 211-218.

Russo J, Ao X, Grill C \& Russo H 1999 Pattern of distribution of cells positive for estrogen receptor alpha and progesterone receptor in relation to proliferating cells in the mammary gland. Breast Cancer Research and Treatment $\mathbf{5 3} 217-227$.

Seagroves N, Lydon JP, Hovey RC, Vonderhaar BK \& Rosen JM $2000 \mathrm{C} / \mathrm{EBPb}$ ta (CCAAT/enhancer binding protein) controls cell fate determination during mammary gland development. Molecular Endocrinology 14 359-368.

Shoker BS, Jarvis C, Clarke RB, Anderson E, Hewlett J, Davies MP, Sibson DR \& Sloane JP 1999 Estrogen receptor-positive proliferating cells in the normal and precancerous breast. American Journal of Pathology 155 1811-1815.
Sinha DK, Pazik JE \& Dao TL 1988 Prevention of mammary carcinogenesis in rats by pregnancy: effect of full-term and interrupted pregnancy. British Journal of Cancer 57 390-394.

Sivaraman L, Stephens LC, Markaverich BM, Clark JA, Krnacik S, Conneely OM, O'Malley BW \& Medina D 1998 Hormoneinduced refractoriness to mammary carcinogenesis in Wistar-Furth rats. Carcinogenesis 19 1573-1581.

Yang J, Yoshizawa K, Nandi S \& Tsubura A 1999 Protective effects of pregnancy and lactation against $\mathrm{N}$-methyl-N-nitrosourea-induced mammary carcinomas in female Lewis rats. Carcinogenesis $\mathbf{2 0}$ 623-628.

Received 19 May 2001

Accepted 25 June 2001 